\title{
Review of Thoracic Endovascular Aneurysm Repair (TEVAR), Spinal Cord Ischemia (SCI), Cerebrospinal Fluid (CSF) Drainage and Blood Pressure (BP) Augmentation
}

\author{
R. Englund \\ Department of Vascular Surgery, St George Private Hospital, Kogarah, Australia \\ Email: renglund@ihug.com.au
}

How to cite this paper: Englund, R. (2017) Review of Thoracic Endovascular Aneurysm Repair (TEVAR), Spinal Cord Ischemia (SCI), Cerebrospinal Fluid (CSF) Drainage and Blood Pressure (BP) Augmentation. Surgical Science, 8, 73-81.

https://doi.org/10.4236/ss.2017.82009

Received: December 21, 2016

Accepted: January 19, 2017

Published: January 22, 2017

Copyright $\odot 2017$ by author and Scientific Research Publishing Inc. This work is licensed under the Creative Commons Attribution International License (CC BY 4.0).

http://creativecommons.org/licenses/by/4.0/

\begin{abstract}
The object of this review is to examine the role of TEVAR in causing SCI. The anatomy and physiology of blood flow to the spinal cord is examined. The role of auto regulation of blood flow within the spinal cord is also examined. This review examines the reported results from the scientific literature of the effect of thoracic aortic aneurysm repair on spinal cord blood flow. In the light of these findings several conclusions can reasonably be reached. These conclusions are that the development of SCI can reasonably be predicted based on complexity and extent of the TEVAR procedure performed and BP augmentation and CSF drainage can significantly reduce the impact of SCI.
\end{abstract}

\section{Keywords}

Thoracic Endovascular Aortic Aneurysm Repair, Spinal Cord Ischemia, Means Systemic Arterial Blood Pressure, Cerebrospinal Fluid Drainage, Collateral Network

\section{What Is Spinal Cord Ischemia (SCI)}

Ischemia is the stopping of blood, originally the staunching of bleeding, now only local anaemia; deficiency of blood supply to (a part of) an organ. Therefore spinal cord ischemia is reduction or cessation of blood supply to part or whole of the spinal cord. When blood supply is lost there is usually a commensurate loss of function. With respect to the spinal cord this usually means the development of paraparesis or paraplegia. Ultimately profound reduction in blood supply results in infarction and death of the organ. 


\section{How Is the Spinal Cord Supplied with Blood}

Blood supply to the spinal cord is predicated on 2 systems. The first is the anatomical structures of arteries and veins which supply oxygenated blood to the spinal cord and removed deoxygenated blood back to the heart. The second is the auto regulatory mechanisms the control the microcirculation of blood vessels within the spinal cord itself.

The anatomical layout of spinal cord blood supply is examined by Griepp RB \& Griepp EB [1] "the major cephalic inputs into the spinal cord blood supply include the vertebral arteries and other branches of the subclavian and carotid arteries that reach the cord in its upper portion. The input to the central cord is from multiple segmental branches (the intercostal and lumbar arteries), including a large branch in the lower thoracic or upper abdominal aorta now designated as the artery of Adamkiewicz. The distal spinal cord and caudaequina are supplied primarily from the hypogastric arteries and their branches."

Lazorthes G, Gouaze A, Zadeh JO et al. [2] espoused the concept of the collateral network of the spinal cord consisting of [1] arteries in the spinal cord, [2] perivertebral tissues and [3] paraspinal muscles with inputs at the 3 levels as outlined by Griepp and Griepp above. They documented the dynamic nature of spinal cord blood supply input and also the possibility of steel syndrome through the same system. The collateral network is likely to be significantly influenced by spinal cord vascular auto regulation.

Spinal cord vascular auto regulation is based on 3 factors [1] systemic arterial pressure, [2] central venous pressure and [3] cerebrospinal fluid pressure. Griepp and Griepp [1] have made the statement "Arterial perfusion pressures in the high physiologic range have been adopted by almost all aortic surgeons." And "Perfusion through the collateral network is undoubtedly enhanced by high perfusion pressures. Most surgeons insist that mean arterial pressures be maintained at least at $80 \mathrm{mmHg}$ and perhaps as high as 90 to $100 \mathrm{mmHg}$ during the operative period."

Lazorthes G, Gouaze A, Zadeh JO et al. [2] examined 10 patients for a consecutive series of 858 thoracoabdominal repairs (June1990-June 2006). These patient all had delayed onset paraplegia within 48 hours postoperatively. In all 10 patients somato-sensory evoked potentials were intact at the completion of surgery. A control group of 10 matched subjects without spinal cord injury were compared for hemodynamic characteristics and extent of segmental artery sacrifice. The only significant difference between these 2 groups was a higher mean central venous pressure in the paraplegia group during the first 5 hours postoperatively.

Cerebrospinal fluid (CSF) is produced by the choroid plexus and the ependymal cells of the brain. The choroid plexus is essentially a venous plexus and CSF occupies the subarachnoid space of the central nervous system. Ependymal cells actively secrete sodium into the lateral ventricles creating osmotic pressure which draws in water and chloride. About $500 \mathrm{mls}$ of CSF is produced in 24 hours but CSF is constantly reabsorbed so that $100 \mathrm{mls}$ to $160 \mathrm{mls}$ is present at 
any one time. Recently Klaric M, Oreskovic D [3] have suggested that CSF is produced in the entire central nervous system as a consequence of water filtration through capillary walls and is controlled by AQP4. AQp4 is a membrane protein that controls conduction of water through membranes [4]. AQp4 is up regulated by direct insult to the central nervous system. Circulation of CSF is dependent on the cardiac cycle and is bidirectional.

Therefore CSF formation and pressure as well as reabsorption are influenced by the differential between arterial and venous pressure and modified by activity of AQp4. Spinal cord perfusion pressure is determined by the relationship between arterial pressure in the collateral network, which is also influenced by central venous pressure, and pressure of CSF in the subarachnoid space. The interplay between these factors may result in subtle variation of spinal perfusion pressure and therefore spinal cord perfusion.

\section{What Are the Risk Factors for Spinal Cord Ischaemia}

In 1998 Ishmura S, Kawaguchi S, Koizumi N Obitsu Y \& Ishikawa M, [5] reported on the use of a retrievable aortic occluder to predict the development of spinal cord ischemia based on the end point of somato-sensory evoked potentials. In 2001 Gravereaux EC, Faries PL, Burks JA et al. [6] with an experience of 53 patients concluded "concomitant or previous abdominal aortic aneurysm repair and long segment thoracic aortic occlusion appear to be important risk factors (for the development of SCI). Chiesa R, Melissano G, et al. [7] reported on an experience over 5 years of 103 patients elective endovascular repair of the thoracic aorta. They concluded that "Peri-operative hypotension (MAP $<70$ $\mathrm{mmHg}$ ) was found to be a significant predictor of spinal cord ischemia". They also indicated that "patients with previous or synchronous abdominal aortic repair" were at risk of developing SCI. They also indicated the length of aortic coverage may be an important factor in the development of SCI. Buth J, Harris $\mathrm{PL}$, Hobo $\mathrm{R}$ et al. [8] made the following statement "independent correlation with SCI was observed for 4 factors [1] left subclavian artery covering without revascularisation (odds ratio $[\mathrm{OR}], 3.9 ; p=0.027)$, [2] renal failure $(\mathrm{OR}, 3.6 ; p=$ $0.02)$, [3] concomitant open abdominal aortic surgery (OR, 5.5; $p=0.037)$ and [4] 3 or more stent grafts used (OR, 3.5; $p=0.043)$. Some of these findings were confirmed by Kawaharada N, Morishita K, Kurimoto Y et al. [9] concluded "Prior thoracic aortic replacement was found to be a significant predictor of spinal cord ischemia”. Amabile P, Grisoli D, Giorgi R et al. [10] in an experience of 67 patients concluded "Multivariate logistic regression analysis showed that length of aortic coverage was the only independent significant predictor of SCI. ROC curve analysis revealed $205 \mathrm{~mm}$ of aortic length coverage as the threshold for increased risk of postoperative SCI $(p=0.001)$, with specificity and sensitivity of 95.2 and $80 \%$ respectively". Similarly Feezor RJ, Martin TD, Hess PJ et al. [11] came to the following conclusion "patients with permanent SCI had a greater absolute $(260.5 \pm 40.9$ vs $195.8 \pm 81.6 \mathrm{~mm}, p=0.002)$ and proportionate $(88.8 \% \pm 12.1 \%$ vs $67.6 \% \pm 24.0 \%, p=0.001)$ length of aortic coverage”. Also 
Greenberg RK, Lu Q, Roselli EE et al. [12] Found "No significant difference in the incidence of mortality or SCI was found between ER and SR techniques. The strongest factor associated with SCI remains the extent of the disease". Drinkwater SL, Goebells A, Haydar A et al. [13]. Concluded “ ... of the prespecified factors investigated for association with SCI, only percentage of aortic coverage was significantly associated with the incidence of SCI; adjusted odds ratio per $10 \%$ increase in aorta covered $=1.78$ [95\% CI $1.81-2.71$ ], $p=0.007$ ". In 2011 Ullery BW, Cheung AT, Fairman RM et al. [14]. In a study of 424 patients undergoing TEVAR stated "Multivariate regression analysis demonstrated chronic renal insufficiency to be independently associated with SCI (odds ratio [OR], 4.39; 95\% confidence interval [CI], $1.2-16.6, p=0.029$ )".

In summary the factors that are clearly demonstrated within the scientific literature to be predictors for development of SCI are the extent of coverage of the aorta with a threshold of $205 \mathrm{~mm}$ absolute coverage or doubling for every $10 \%$ of aortic coverage. Coverage of the subclavian artery without revascularisation and prior or concomitant abdominal aortic surgery have also been demonstrated to be associated with the development of SCI. The association between chronic renal failure and the development of SCI is most likely to be a reflection of the extent of involvement of the aortic disease process. The overarching thesis is the impact all these factors have on perfusion pressures provided to the spinal collateral network from the proximal, mid segmental and distal hypogastric arterial supply of blood flow.

\section{What Is the Incidence of Spinal Cord Ischemia}

The reported incidence of SCI is variable because each reported series consists of variable numbers of patients with vary incidence of risk factors and varying incidence of interventions to prevent or ameliorate SCI. However in a review of [15] Sullivan TM and Sundt TM looked at 28 studies from 1999 to 2005 which included 1895 patients. Twelve of these studies reported a zero incidence of paraplegia/paraparesis but only 1 of these studies contained more than 50 patients. Overall the rate of paraplegia/paraparesis was $2.7 \%$ and varied from $12.5 \%$ to zero. Since then Etz CD, Halstead CD, Spielvogel D et al., [16] reported 2\% paraplegia rate for 100 consecutive patients using intra-operative monitoring with Motor evoked potentials and somato-sensory evoked potentials and treatment with blood pressure manipulation and routine CSF drainage for between 28 and 72 hours postoperatively. Bavaria JE, Appoo JJ, Makaroun MS et al., [17] reported on 140 patients undergoing TEVAR and 94 open surgical control patients. The rate of SCI was 3\% in the TEVAR group versus $14 \%$ in the open surgical group. Conrad MF, Crawford RS, Davison K et al. [18] reported retrospective experience of 445 patients treated between 1987 and 2005. SCI occurred in $13.2 \%$ and sustained major paraplegia occurred in $9.5 \%$ of patients. They reported that epidural cooling significantly reduced the risk of SCI. Buth J et al. from [8] the EUROSTAR registry reported 2.5\% SCI for the 606 patients in their study. Kawaharada et al. [9] in 144 patients undergoing thoracic stent graft re- 
ported 3.6\% paraparesis/paraplegia. Amabile P et al. [10] reported 7.5\% SCI in 67 consecutive patients. No patients in this series had intra-operative neurological monitoring or CSF drainage. In 2008 Etz CD et al. [16] from 858 patients undergoing repair in patients treated between 1990 and 2006 report a paraplegia rate of 2.7\%. In 2008 Matsumura JS, Cambria RP, Dake MD et al. [19] reported the results of a trial comparing open with endovascular repair for thoracic aortic pathology which included both aneurysms and large aortic ulcers. Patients ( $\mathrm{n}=$ $230)$ were randomised into either TEVAR $(n=160)$ or open surgical repair $(n=$ 70). There was no significant difference in the incidence of SCI between the 2 groups. Two patients in the TEVAR group developed paraplegia and 7 developed paraparesis (5.6\% SCI rate). Freezor et al. [11] in Dec 2008 reported SCI rate of $10 \%$ in a retrospective series of 326 TEVAR treated patients. Greenberg RK et al. [12] reported a comparison study of consecutive patients $(n=724)$ treated by either open operation or TEVAR. There was no difference with respect to the incidence of SCI between the 2 groups ( $7.5 \%$ vs $4.3 \%$ respectively). In 2010 Drinkwater SL et al. [13] reporting on 235 patients found permanent paraplegia rate of 5.5\% and an overall SCI incidence of $9.8 \%$. In 2011 Ullery BW et al. [14] in 424 patients treated between 2002 and 2010 reported SCI rate of $2.8 \%$.

In summary one could reasonably assume a baseline SCI rate of between $2 \%$ to $3 \%$ with subsequent adjustment upwards for the presence of the risk factors length of coverage of the aortic segment, previous or concomitant aortic surgery, presence of chronic renal failure and coverage of subclavian artery or hypogastric vessels distally without revascularisation. The presence of all these factors could result in an incidence of SCI $>10 \%$.

\section{What Can Be Done to Prevent SCI?}

The techniques available to mitigate SCI are (1) distal aortic perfusion (2) implantation or preservation of segmental arterial supply to the spinal cord (3) epidural cooling (4) Blood pressure and hemodynamic manipulation (5) CSF drainage.

In 1982 Cunningham JN, Laschinger JC, Merkin HA et al. [20] described the use of somat-osensory evoked potentials to detect SCI and reversed these changes by use of heparinised shunt and femoro-femoral shunt. Subsequently a number of studies have claimed to demonstrate the benefit of distal aortic perfusion during thoracoabdominal aneurysm repair, [21] [22]. However distal aortic perfusion is not likely to be relevant to endovascular repair of the thoracic aorta. Further distal aortic perfusion is probably of no benefit in those patients experiencing delayed onset paraplegia. In 2004 Coselli JS et al. [23] reported on 15 year experience of 387 patients and made the statement "the use of LHB during DTAA repair did not reduce the incidence of spinal cord injury."

Although re-implantation of intercostal arteries would seem to be a reasonable approach to the avoidance of SCI in $2006 \mathrm{Etz}$ CD et al. [16] reviewed 100 consecutive patients undergoing thoracic aneurysm repair involving serial seg- 
mental artery sacrifice. They claimed "sacrifice-without re-implantation- of as many as 15 intercostal and lumbar arteries during TAA/A is safe". As with distal aortic perfusion this technique is not relevant to the performance of TEVAR.

The use of epidural cooling has been reported by Cambria RP, Davison JK, Carter C et al. [24]. They treated 170 consecutive patients by this technique by open operation reporting 7\% SCI. This technique is unlikely to have much impact on cases of delayed paraplegia. Additionally most reports of the use of this technique have been associated with the use of other adjunctive measures.

Blood pressure and hemodynamic manipulation is designed to improve the perfusion pressure presented to the spinal collateral vascular network. In 2011 Ullery et al. [14] concluded "Early detection and treatment of SCI with blood pressure augmentation alone or in combination with CSF drainage was effective in most patients, with the majority achieving complete, long term neurological recovery". Similarly Hnath et al. [25] in 2008 concluded "Peri-operative CSF drainage with augmentation of systemic blood pressures may have a beneficial role in reducing the risk of paraplegia in patients undergoing thoracic aortic stent graft placement". Further Griepp et al. [1] stated in 2007 "Arterial pressure in the high physiological range have been adopted by almost all aortic surgeons." And "Perfusion pressure through the collateral network is undoubtedly enhanced by high perfusion pressure. Most surgeons now insist that mean arterial pressures be maintained at least at $80 \mathrm{mmHg}$ and perhaps as high as 90 to 100 mmHg during the operative procedure. In 2005 Chiesa et al. [7] stated "perioperative hypotension (MAP $<70 \mathrm{mmHg}$ ) was found to be a significant predictor of spinal cord ischemia; hence careful monitoring and prompt correction of arterial pressure may prevent the development of paraplegia." Cheung et al. (2005) [26] noted that SCI occurred in 5 patients of their series of 75 patients. Two had full recovery in response to arterial augmentation alone. Two had full recovery and one had near complete recovery in response to arterial pressure augmentation and CSF drainage.

In 2004 Cina CS, Abouzahr L, Arena GO et al. [27] conducted a review of the use of CSF drainage to prevent SCI. They found" Three RCTs reported 289 patients with type I or type II TAAA. Lower limb neurological deficits occurred in $12 \%$ patients who underwent CSF drainage and $33 \%$ of control subjects (number needed to treat, 9; 95\% confidence interval [C.I.], 5 - 50). The pooled odds ratio (OR) for the development of paraplegia in patients in the CSF drainage group was 0.35 ( $p=0.05$; 95\%C.I., 0.12 - 0.99). Similar results were found in 5 cohort studies with a control group (pooled OR, 0.26; $p=0.0002$; 95\%C.I., $0.17-0.53$ ). When all studies were considered together the pooled OR of TA and TAAA was 0.3 (95\% CI, 0.17 - 0.54). Some have advocated the selective use of CSF drainage. Sullivan and Sundt (2006) have suggested that the indications for CSF drainage were 1) Anticipated endograft coverage T9-T12 (location of anterior spinal artery); 2) Coverage of long segment of thoracic aorta; 3) Compromised collateral pathway (e.g. previous infrarenal aortic aneurysm repair); 4) Symptomatic spinal ischemia (in a patient who did not have a drain placed preoperatively). 


\section{What Are the Risks Associated with CSF Drainage}

In 2009 Estrera AL, Shienbaum R, Miller CC et al. [28] outlined the use of CSF drainage in 1105 of 1107 patients on an intention to treat basis. "The CSF leaks with spinal headache, CSF leak without spinal headache, spinal headache, intracranial hemorrhage, catheter fracture, and meningitis occurred in $6(0.54 \%), 1$ $(0.1 \%), 2(0.2 \%), 5(0.45 \%), 1(0.1 \%)$ and $2(0.2 \%)$ of cases , respectively." The overall complication rate was 1.7\%. Further Wynn MM, Mell MW, Tefera G et al, (26) reported a mortality rate from spinal fluid drainage complications as $0.6 \%$ (3 of 482) [29].

\section{Conclusion}

The performance of TEVAR is associated with a $2 \%$ to $3 \%$ incidence of spinal cord ischemia. This risk increases with clearly identified factors. These factors are the extent of coverage of the aorta by stent graft, prior aortic surgery, the performance of debranching procedures, the presence of renal impairment and the presence of hypotension. Peri-operatively the maintenance of mean systemic arterial blood pressure at $90 \mathrm{mmHg}$ or more can prevent the development of spinal cord ischemia in many cases. CSF drainage is an important adjunct to the prevention of SCI in high risk cases or where blood pressure management has been optimal but SCI has developed.

\section{References}

[1] Griepp, R.B. and Griepp, E.B. (2007) Spinal Cord Perfusion and Protection during Descending Thoracic and Thoracoabdominal Surgery: The Collateral Network Concept. The Annals of Thoracic Surgery, 83, S865-S869.

https://doi.org/10.1016/j.athoracsur.2006.10.092

[2] Lazorthes, G., Gouaze, A., Zadeh, J.O., et al. (1971) Arterial Vascularisation of the Spinal Cord: Recent Studies of the Anatomic Substitution Pathways. Journal of Neurosurgery, 35, 253-262. https://doi.org/10.3171/jns.1971.35.3.0253

[3] Klaric, M. and Oreskovic, D. (2014) A New Look at Cerebrospinal Fluid Movement. Fluid Barriers CNS, 11.

[4] Papadopoulos, M.C. and Verkman, A.S. (2013) Aquaporin Water Channels in the Nervous System. Nature Reviews Neuroscience, 14, 265-277. https://doi.org/10.1038/nrn3468

[5] Ishmura, S., Kawaguchi, S., Koizumi, N., Obitsu, Y. and Ishikawa, M. (1998) Preliminary Report on Prediction of Spinal Cord Ischemia in Endovascular Stent Graft Repair of Thoracic Aortic Aneurysm by Retrievable Stent Graft. Journal of Thoracic and Cardiovascular Surgery, 115, 811-818. https://doi.org/10.1016/S0022-5223(98)70360-5

[6] Gravereaux, E.C., Faries, P.L., Burks, J.A., et al. (2001) Risk of Spinal Cord Ischemia after Endograft Repair of Thoracic Aortic Aneurysms. Journal of Vascular Surgery, 34, 997-1003 https://doi.org/10.1067/mva.2001.119890

[7] Chiesa, R., Melissano, G., et al. (2005) Spinal cord Ischemia after Elective StentGraft Repair of the Thoracic Aorta. Journal of Vascular Surgery, 42, 11-17.

[8] Buth, J., Harris, P.L., Hobo, R., et al. (2007) Neurological Complications Associated with Endovascular Repair of Thoracic Pathology: Incidence of Risk Factors. A Study 
from the European Collaborators on Stent/Graft Repair (Eurostar) Registry. Journal of Vascular Surgery, 46, 1103-1111. https://doi.org/10.1016/j.jvs.2007.08.020

[9] Kawaharada, N., Morishita, K., Kurimoto, Y., et al. (2007) Spinal Cord Ischemia after Elective Endovascular Stent Graft Repair of the Thoracic Aorta. European Journal Cardio-Thoracic Surgery, 31, 998-1003. https://doi.org/10.1016/j.ejcts.2007.01.069

[10] Amabile, P., Grisoli, D., Giorgi, R., et al. (2008) Incidence and Determinants of Spinal Cord Ischemia in Stent Graft Repair of the Thoracic Aorta. European Journal of Vascular and Endovascular Surgery, 35, 455-461. https://doi.org/10.1016/j.ejvs.2007.11.005

[11] Feezor, R.J., Martin, T.D., Hess, P.J., et al. (2008) Extent of Aortic Coverage and Incidence of Spinal Cord Ischemia after Thoracic Endovascular Aneurysm Repair. Annals of Thoracic Surgery, 86, 1809-1814. https://doi.org/10.1016/j.athoracsur.2008.09.022

[12] Greenberg, R.K., Lu, Q., Roselli, E.E., et al. (2008) Contemporary Analysis of Descending Thoracic and Thoracoabdominal Aneurysm Repair. A Comparison of Endovascular and Open Techniques. Circulation, 118, 808-817. https://doi.org/10.1161/CIRCULATIONAHA.108.769695

[13] Drinkwater, S.L., Goebells, A., Haydar, A., et al. (2010) The Incidence of Spinal Cord Ischemia Following Thoracic and Thoracoabdominal Aortic Endovascular Intervention. European Journal of Vascular and Endovascular Surgery, 40, 729-735. https://doi.org/10.1016/j.ejvs.2010.08.013

[14] Ullery, B.W., Cheung, A.T., Fairman, R.M., et al. (2011) Risk Factors, Outcome, and Clinical Manifestations of Spinal Cord Ischemia Following Thoracic Endovascular Repair. Journal of Vascular Surgery, 54, 677-684. https://doi.org/10.1016/j.jvs.2011.03.259

[15] Sullivan, T.M. and Sundt, T.M. (2006) Complication of Thoracic Aortic Endografts: Spinal Cord Ischemia and Stroke. Journal of Vascular Surgery, 43, 85a-88a. https://doi.org/10.1016/j.jvs.2005.10.048

[16] Etz, C.D., Halstead, C.D., Spielvogel, D., et al. (2006) Thoracic and Thoracoabdominal Aneurysm Repair: Is Reimplantation of Spinal Cord Arteries a Waste of Time. Annals of Thoracic Surgery, 82, 1670-1678. https://doi.org/10.1016/j.athoracsur.2006.05.029

[17] Bavaria, J.E., Appoo, J.J., Makaroun, M.S., et al. (2007) Endovascular Stent Grafting versus Open Surgical Repair of Thoracic Aortic Aneurysms in Low Risk Patients: A Multicentre Comparative Trial. The Journal of Thoracic and Cardiovascular Surgery, 133, 369-377. https://doi.org/10.1016/j.jtcvs.2006.07.040

[18] Conrad, M.F., Crawford, R.S., Davison, K., et al. (2007) Thoracoabdominal Aneurysm Repair: A Twenty Year Experience. Annals of Thoracic Surgery, 83, s856-s861. https://doi.org/10.1016/j.athoracsur.2006.10.096

[19] Matsumura, J.S., Cambria, R.P., Dake, M.D., et al. (2008) International Controlled Trial of Thoracic Endovascular Aneurysm Repair with the Zenith TX2 Endovascular Graft: 1 Year Results. Journal of Vascular Surgery, 47, 247-257. https://doi.org/10.1016/j.jvs.2007.10.032

[20] Cunningham, J.N., Laschinger, J.C., Merkin, H.A., Coselli, J.S. and Safi, H. (1982) Measurement of Spinal Cord Ischemia during Operations on the Thoracic Aorta. Annals of Surgery, 196, 285-293. https://doi.org/10.1097/00000658-198209000-00007

[21] Svennson, L.G., Crawford, E.S., Hess, K.R., et al. (1993) Experience with 1509 Patients Undergoing Thoracoabdominal Aortic Aneurysm Operations. Journal of 
Vascular Surgery, 17, 357-370. https://doi.org/10.1016/0741-5214(93)90421-H

[22] Livesay, J.L., Cooley, D.A., Ventemiglia, R.A. et al. (1995) Surgical Experience in Descending Thoracic Aneurysmectomy with and without Adjuncts to Avoid Ischemia. Annals of Thoracic Surgery, 39, 37-46. https://doi.org/10.1016/S0003-4975(10)62520-9

[23] Coselli, J.S., LeMaire, S.A., Conklin, L.D. and Adams, G. (2004) Left Heart Bypass during Descending Thoracic Aortic Aneurysm Repair Does Not Reduce the Incidence of Paraplegia. Annals of Thoracic Surgery, 77, 1298-1303. https://doi.org/10.1016/j.athoracsur.2003.10.033

[24] Cambria, R.P., Davison, J.K., Carter, C., et al. (2000) Epidural Cooling for Spinal Cord Protection during Thoracoabdominal Aneurysm Repair: A Five Year Experience. Journal of Vascular Surgery, 31, 1093-1102. https://doi.org/10.1067/mva.2000.106492

[25] Hnath, J.C., Metha, M., Taggert, J.B., et al. (2008) Strategies to Improve Spinal Cord Ischemia in Endovascular Thoracic Aortic Repair: Outcomes of a Prospective Cerebrovascular Fluid Drainage Protocol. Journal of Vascular Surgery, 48, 836-840. https://doi.org/10.1016/j.jvs.2008.05.073

[26] Cheung, A.T., Pochettino, A., McGarvey, M.L., et al. (2005) Strategies to Manage Paraplegia Risk after Endovascular Stent Repair of Descending Thoracic Aortic Aneurysms. Annals of Thoracic Surgery, 80, 1280-1289. https://doi.org/10.1016/j.athoracsur.2005.04.027

[27] Cina, C.S., Abouzahr, L., Arena, G.O., et al. (2004) Cerebrospinal fluid drainage to prevent paraplegia during thoracic and thoracoabdominal aneurysm surgery: A systematic review and meta-analysis. Journal of Vascular Surgery, 40, 36-44. https://doi.org/10.1016/j.jvs.2004.03.017

[28] Estrera, A.L., Shienbaum, R., Miller, C.C., et al. (2009) Cerebrospinal Fluid Drainage during Thoracic Aortic Repair: Safety and Current Management. Annals of Thoracic Surgery, 88, 9-15. https://doi.org/10.1016/j.athoracsur.2009.03.039

[29] Wynn, M.M., Mell, M.W., Tefera, G., Hoch, J. and Acher, C. (2009) Complications of Spinal Fluid Drainage in Thoracoabdominal Aortic Aneurysm Repair: A Report of 486 Patients Treated from 1987 to 2008. Journal of Vascular Surgery, 49, 29-35. https://doi.org/10.1016/j.jvs.2008.07.076

\section{Submit or recommend next manuscript to SCIRP and we will provide best service for you:}

Accepting pre-submission inquiries through Email, Facebook, LinkedIn, Twitter, etc. A wide selection of journals (inclusive of 9 subjects, more than 200 journals)

Providing 24-hour high-quality service

User-friendly online submission system

Fair and swift peer-review system

Efficient typesetting and proofreading procedure

Display of the result of downloads and visits, as well as the number of cited articles

Maximum dissemination of your research work

Submit your manuscript at: http://papersubmission.scirp.org/

Or contact ss@scirp.org 